\title{
Analysis of Thrombotic Adverse Reactions of COVID-19 AstraZeneca Vaccine Reported to EudraVigilance Database
}

\author{
Mansour Tobaiqy ${ }^{1, *(\mathbb{D})}$, Hajer Elkout ${ }^{2}$ and Katie MacLure ${ }^{3}$ (i) \\ 1 Department of Pharmacology, College of Medicine, University of Jeddah, Jeddah 45311, Saudi Arabia \\ 2 Department of Family and Community Medicine, Medical Faculty, University of Tripoli, Tripoli 13275, Libya; \\ H.elkout@yahoo.com \\ 3 Independent Research Consultant, Aberdeen AB32 6RU, UK; katiemaclure@outlook.com \\ * Correspondence: mtobaiqy@uj.edu.sa
}

Citation: Tobaiqy, M.; Elkout, H.; MacLure, K. Analysis of Thrombotic Adverse Reactions of COVID-19 AstraZeneca Vaccine Reported to EudraVigilance Database. Vaccines 2021, 9, 393. https://doi.org/ $10.3390 /$ vaccines 9040393

Academic Editors: Ralph A. Tripp, Steven B. Bradfute and Scott Anthony

Received: 20 March 2021

Accepted: 13 April 2021

Published: 16 April 2021

Publisher's Note: MDPI stays neutral with regard to jurisdictional claims in published maps and institutional affiliations.

Copyright: (C) 2021 by the authors. Licensee MDPI, Basel, Switzerland. This article is an open access article distributed under the terms and conditions of the Creative Commons Attribution (CC BY) license (https:/ / creativecommons.org/licenses/by/ $4.0 /)$.

\begin{abstract}
The development of safe, effective, affordable vaccines against COVID-19 remains the cornerstone to mitigating this pandemic. Early in December 2020, multiple research groups had designed potential vaccines. From 11 March 2021, several European countries temporarily suspended the use of the Oxford-AstraZeneca vaccine amid reports of blood clot events and the death of a vaccinated person, despite the European Medicines Agency (EMA) and the World Health Organization's assurance that there was no indication that vaccination was linked. This study aimed to identify and analyse the thrombotic adverse reactions associated with the Oxford-AstraZeneca vaccine. This was a retrospective descriptive study using spontaneous reports submitted to the EudraVigilance database in the period from 17 February to 12 March 2021. There were 54,571 adverse reaction reports, of which 28 were associated with thrombotic adverse reactions. Three fatalities were related to pulmonary embolism; one fatality to thrombosis. With 17 million people having had the AstraZeneca vaccine, these are extremely rare events The EMA's Pharmacovigilance Risk Assessment Committee (18 March 2021) concluded that the vaccine was safe, effective and the benefits outweighed the risks. Conducting further analyses based on more detailed thrombotic adverse event reports, including patients' characteristics and comorbidities, may enable assessment of the causality with higher specificity.
\end{abstract}

Keywords: COVID-19; adverse events; adverse drug reaction; thrombotic; vaccine

\section{Introduction}

The pandemic of SARS-CoV 2, the causative agent of COVID-19, poses an unprecedented challenge to world economies and community health. The development of safe, effective, affordable vaccines against COVID-19 remains the cornerstone to mitigating new viral strains in this pandemic crisis and re-establishing normality going forward. Several pharmacological therapeutics were suggested early in the pandemic for the treatment of this disease such as remdesivir, favipiravir, hydroxychloroquine, tocilizumab, lopinavirritonavir (LPV / RTV) and convalescent plasma [1-4]. By early December 2020, multiple research groups had designed potential vaccines against COVID-19, with most in the early stages of approval by worldwide pharmaceutical regulatory authorities [5,6].

Chimpanzee adenovirus encoding the SARS-CoV-2 spike glycoprotein (ChAdOx1-S) $[7,8]$ is the Oxford-AstraZeneca vaccine designed to prevent COVID-19 infection. It was authorised by the European Medicines Agency (EMA) for use across the European Union (EU) following endorsement by the European Commission on 29 January $2021[9,10]$. The efficacy and safety of the AstraZeneca vaccine was determined following a short-term analysis of data pooled from clinical trials that were conducted in the United Kingdom, Brazil, and South Africa [11]. Approximately 23,745 participants aged 18 years and older had been randomised and received either the COVID-19 vaccine AstraZeneca or a control. Participants who had one or more comorbidities had a vaccine efficacy of $73.4 \%(95 \% \mathrm{CI}$ : $48.5 ; 86.3)$; and in the 
updated analysis, the vaccine efficacy in participants with one or more comorbidities was $62.7 \%$ (95\% CI: 44.8; 74.8) [11]. The most frequently reported adverse reactions (Ars) from first vaccination were: injection site tenderness $(63.7 \%)$, injection site pain $(54.2 \%)$, fatigue $(53.1 \%)$, headache $(52.6 \%)$, malaise $(44.2 \%)$, myalgia $(44.0 \%)$, pyrexia (includes feverishness $(33.6 \%)$ and fever $\left.>38{ }^{\circ} \mathrm{C}(7.9 \%)\right)$ [11]. The majority of Ars were mild to moderate in severity and resolved within a short period following the vaccination [11]. Adverse reactions to second vaccinations were of the same nature but "milder and less frequent" [11].

Since 11 March 2021, several European countries (including Denmark, France, Italy, Latvia, Norway, Spain, Sweden and The Netherlands) temporarily suspended the use of the Oxford-AstraZeneca COVID-19 vaccine amid reports of blood clot events and the death of a vaccinated person $[12,13]$. Within a week, some 18 countries worldwide had suspended or age-restricted use of the vaccine. The list includes Iceland, Bulgaria, The Democratic Republic of Congo, Ireland, Indonesia, German, Cyprus, Portugal, Slovenia, Luxembourg and Thailand [14]. This precautionary measure was taken despite the European Medicines Agency's (EMA) and the World Health Organization's assurance that there was no indication that vaccination was linked to thromboembolic events [5,9]. According to the AstraZeneca COVID-19 vaccine summary of product characteristics (for healthcare professionals), blood and lymphatic system disorders as adverse reactions were uncommon, however, no details on the occurrences and frequencies of these reactions were available at this time [15]. AstraZeneca emphasised the safety of their vaccine stating the blood clot prevalence was "much lower than would be expected to occur naturally in a general population of this size" [15].

Traditionally, the monitoring of vaccine safety after licensure is subject to a combination of passive and active surveillance. The passive surveillance system is the basis of pharmacovigilance, which comprises the databases into which spontaneous reports of suspected adverse drug reactions (ADRs) and adverse events following immunisation (AEFI) from physicians and patients are collected [16]. EudraVigilance (EV) is a passive pharmacovigilance system for collecting, managing and analysing suspected ADRs and AEFI reports for medicines approved in the EU and it is operated by the EMA [16].

The monitoring of safety reports of drugs and vaccines is critical because clinical trials are designed to assess primarily the efficacy; safety is typically a secondary objective. These trials are able to identify only common adverse events such as local and systemic reactions related to the immunogenicity of the vaccine that occurs shortly after administration. The trials are unlikely to detect rare adverse events that occur with trials in larger populations or delayed reactions that occur a long time after use, therefore pharmacovigilance and postmarketing surveillance is of great importance to detect unusual adverse events $[8,16,17]$.

This study aimed to identify and analyse the thrombotic adverse reactions associated with the Oxford-AstraZeneca vaccine following its temporary suspension in several EU countries using the European EV database [12,13].

\section{Materials and Methods}

This was a retrospective descriptive study using spontaneous reports submitted to the EV database in the period from 17 February to 12 March 2021. Data were extracted from the line listing section of reports submitted to the EV in relation to COVID-19 Vaccine AstraZeneca (ChAdOx1-S). The following search terms were applied regardless of age group, gender, geographical area, reporter or level of seriousness: thrombosis; embolism; thromboembolism; embolic and thrombotic [16]. Data were cleaned by removing irrelevant columns and fields, tabulated and presented according to the type of thrombosis and clinical outcome, by gender and age.

Ethical consideration: Open access data were used, therefore no access authorisation was requested. The access policy of EMA states that "No authorisation for accessing the ICSR (Level 1) data set by means of the adrreports.eu portal is required i.e., all academic researchers can access adverse reaction data of interest." [18] 


\section{Results}

Overall, there were 54,571 adverse reaction reports for ChAdOx1-S reported to the EV database. The total number of thromboembolic reports was 28 , of which $19(67 \%)$ were submitted by healthcare professionals. More than half $(n=16 ; 57 \%)$ of the reports pertained to people aged over 85 years; 13 (47\%) reports were from within the EU (Tables 1 and 2).

Table 1. Summary of demographics of the EudraVigilance (EV) database reported Astra-Zeneca vaccine adverse drug reaction (ADR) events $(N=28)$.

\begin{tabular}{ccc}
\hline Variable & Level & $\boldsymbol{n}(\mathbf{\%})$ \\
\hline \multirow{2}{*}{ Gender } & Male & $9(32.1)$ \\
& Female & $19(67.9)$ \\
\hline \multirow{2}{*}{ Reporter profession } & Healthcare Professional & $19(67.9)$ \\
& Non-Healthcare Professional & $9(32.1)$ \\
\hline \multirow{2}{*}{ Geographical area } & EU & $13(46.4)$ \\
& Non-EU & $15(53.6)$ \\
\hline \multirow{2}{*}{ Age group of patients } & 18-64 Years & $3(10.7)$ \\
& 65-85 Years & $9(32.1)$ \\
& More than 85 Years & $16(57.1)$ \\
\hline
\end{tabular}

Table 2. Detail of EV database reported AstraZeneca vaccine ADRs $(N=28)$.

\begin{tabular}{|c|c|c|c|c|}
\hline $\begin{array}{l}\text { Receipt Date * } \\
\text { (DD/MM/YYYY) }\end{array}$ & $\begin{array}{l}\text { Primary Source } \\
\text { Qualification }\end{array}$ & $\begin{array}{c}\text { Primary Source } \\
\text { Country }\end{array}$ & Age Group & Sex \\
\hline $17 / 02 / 2021$ & Healthcare Professional & Non-EU & 18-64 Years & Male \\
\hline $18 / 02 / 2021$ & Healthcare Professional & Non-EU & More than 85 Years & Female \\
\hline $23 / 02 / 2021$ & Healthcare Professional & Non-EU & 65-85 Years & Male \\
\hline $02 / 03 / 2021$ & Healthcare Professional & Non-EU & 65-85 Years & Female \\
\hline $03 / 03 / 2021$ & Healthcare Professional & Non-EU & 18-64 Years & Female \\
\hline $06 / 03 / 2021$ & Non-Healthcare Professional & Non-EU & $65-85$ Years & Female \\
\hline $06 / 03 / 2021$ & Healthcare Professional & Non-EU & More than 85 Years & Female \\
\hline $06 / 03 / 2021$ & Non-Healthcare Professional & Non-EU & 65-85 Years & Female \\
\hline $06 / 03 / 2021$ & Healthcare Professional & Non-EU & More than 85 Years & Female \\
\hline $06 / 03 / 2021$ & Non-Healthcare Professional & Non-EU & 65-85 Years & Male \\
\hline $06 / 03 / 2021$ & Healthcare Professional & Non-EU & 65-85 Years & Male \\
\hline $07 / 03 / 2021$ & Non-Healthcare Professional & Non-EU & 18-64 Years & Female \\
\hline $07 / 03 / 2021$ & Healthcare Professional & Non-EU & 18-64 Years & Female \\
\hline $07 / 03 / 2021$ & Healthcare Professional & Non-EU & $65-85$ Years & Female \\
\hline $07 / 03 / 2021$ & Healthcare Professional & Non-EU & $65-85$ Years & Male \\
\hline $08 / 03 / 2021$ & Healthcare Professional & EU & 18-64 Years & Female \\
\hline $08 / 03 / 2021$ & Healthcare Professional & EU & $65-85$ Years & Female \\
\hline $09 / 03 / 2021$ & Healthcare Professional & EU & 18-64 Years & Female \\
\hline $09 / 03 / 2021$ & Healthcare Professional & EU & 18-64 Years & Male \\
\hline $10 / 03 / 2021$ & Healthcare Professional & EU & 18-64 Years & Female \\
\hline $10 / 03 / 2021$ & Non-Healthcare Professional & EU & 18-64 Years & Male \\
\hline $10 / 03 / 2021$ & Non-Healthcare Professional & EU & 18-64 Years & Female \\
\hline $10 / 03 / 2021$ & Healthcare Professional & EU & 18-64 Years & Female \\
\hline $11 / 03 / 2021$ & Healthcare Professional & EU & $18-64$ Years & Male \\
\hline $11 / 03 / 2021$ & Non-Healthcare Professional & EU & 18-64 Years & Female \\
\hline $11 / 03 / 2021$ & Non-Healthcare Professional & EU & 18-64 Years & Female \\
\hline $12 / 03 / 2021$ & Healthcare Professional & EU & 18-64 Years & Female \\
\hline $12 / 03 / 2021$ & Non-Healthcare Professional & EU & 18-64 Years & Male \\
\hline
\end{tabular}

* Date format (date/month/year).

Of the six cases that reported pulmonary embolism, two had a fatal outcome, both in females, one in each of the 18-64 years and over 85 years of age groups. Amongst men, there was one fatality following thrombosis in a patient aged 18-64 years of age. Table 3 
(female; $n=19$ ) and Table 4 (male; $n=9$ ) illustrate the type of reported thromboembolic reaction along with the clinical outcome of cases by age group (Tables 3 and 4).

Table 3. Type of thromboembolic reaction and clinical outcome for female cases by age group $(N=19 / 28)$.

\begin{tabular}{|c|c|c|c|}
\hline Age Group & Reaction Type & Concomitant Conditions & Outcome \\
\hline \multirow{12}{*}{$\begin{array}{c}18-64 \text { Years } \\
(n=12)\end{array}$} & $\begin{array}{l}\text { Cerebral venous sinus thrombosis, } \\
\text { pulmonary embolism }\end{array}$ & $\begin{array}{l}\text { Haemorrhage intracranial, immune } \\
\text { thrombocytopenia, peripheral artery } \\
\text { thrombosis }\end{array}$ & Not Resolved \\
\hline & $\begin{array}{l}\text { Carotid artery thrombosis, } \\
\text { peripheral artery thrombosis }\end{array}$ & $\begin{array}{l}\text { Thrombocytopenia, cerebrovascular } \\
\text { accident }\end{array}$ & Not Resolved \\
\hline & Thrombosis & Chest discomfort, chest pain & Resolved \\
\hline & $\begin{array}{l}\text { Pelvic vein thrombosis, } \\
\text { pulmonary embolism }\end{array}$ & $\begin{array}{l}\text { Thrombocytopenia, blood fibrinogen } \\
\text { decreased, dyspnea, fatigue }\end{array}$ & Resolving \\
\hline & Thrombosis & Uterine haemorrhage & Resolving \\
\hline & Deep vein thrombosis & $\mathrm{N} / \mathrm{A}$ & Unknown \\
\hline & Deep vein thrombosis & $\begin{array}{l}\text { Purpura, pyrexia } \\
\text { (recovered) }\end{array}$ & Resolving \\
\hline & $\begin{array}{l}\text { Deep vein thrombosis, } \\
\text { pulmonary embolism }\end{array}$ & Chest pain, fatigue, pain in extremities & Resolving \\
\hline & $\begin{array}{l}\text { Deep vein thrombosis, } \\
\text { pulmonary embolism }\end{array}$ & $\mathrm{N} / \mathrm{A}$ & Fatal \\
\hline & Deep vein thrombosis & $\mathrm{N} / \mathrm{A}$ & Resolved with Sequelae \\
\hline & Deep vein thrombosis & $\mathrm{N} / \mathrm{A}$ & Resolved \\
\hline & Pelvic venous thrombosis & $\mathrm{N} / \mathrm{A}$ & Not Resolved \\
\hline \multirow{4}{*}{$\begin{array}{l}\text { 65-85 Years } \\
\quad(n=4)\end{array}$} & Deep vein thrombosis & Malaise & Resolving \\
\hline & Thrombosis & Pyrexia & Resolving \\
\hline & Deep vein thrombosis & Pyrexia & Unknown \\
\hline & Deep vein thrombosis & Guillain-Barre syndrome & Unknown \\
\hline \multirow{3}{*}{$\begin{array}{l}\text { More than } 85 \text { Years } \\
\qquad(n=3)\end{array}$} & Deep vein thrombosis & $\mathrm{N} / \mathrm{A}$ & Resolving \\
\hline & $\begin{array}{l}\text { Deep vein thrombosis, pulmonary } \\
\text { embolism }\end{array}$ & $\mathrm{N} / \mathrm{A}$ & Unknown \\
\hline & $\begin{array}{l}\text { Deep vein thrombosis, pulmonary } \\
\text { embolism }\end{array}$ & Lethargy & Fatal \\
\hline
\end{tabular}

Table 4. Type of thromboembolic reaction and clinical outcome for male cases by age group $(N=9 / 28)$.

\begin{tabular}{|c|c|c|c|}
\hline Age Group & Reaction & $\begin{array}{l}\text { Concomitant } \\
\text { Conditions }\end{array}$ & Outcome \\
\hline \multirow{5}{*}{ 18-64 Years } & Thrombophlebitis & \multirow{5}{*}{$\begin{array}{c}\text { Pain } \\
\text { Flu-like illness } \\
\text { Arthralgia, thrombocytopenia, Pain in } \\
\text { extremities, pyrexia } \\
\text { N/A } \\
\text { N/A }\end{array}$} & Resolving \\
\hline & Thrombosis & & Resolving \\
\hline & Thrombosis & & Fatal \\
\hline & Deep vein thrombosis & & Not Resolved \\
\hline & Deep vein thrombosis & & Resolving \\
\hline \multirow{4}{*}{ 65-85 Years } & Thrombophlebitis & $\mathrm{N} / \mathrm{A}$ & Not Resolved \\
\hline & Deep vein thrombosis & $\mathrm{N} / \mathrm{A}$ & Resolving \\
\hline & Thrombosis & $\mathrm{N} / \mathrm{A}$ & Not Resolved \\
\hline & Deep vein thrombosis & Cellulitis, lymphadenitis & Unknown \\
\hline
\end{tabular}

\section{Discussion}

To date, 17 million people in the EU and UK have received at least their first dose of the AstraZeneca vaccine [15]. This study identified 28 thrombotic adverse events linked to 
the use of the AstraZeneca vaccine via the EV database, three of which were fatal outcomes of pulmonary embolism (PE).

Pulmonary embolism (PE) and deep vein thrombosis (DVT) have usually been associated with multiple causative factors. These can be either hereditary or naturally occurring causes including cancer, advanced age, trauma, smoking, inherited or acquired thrombophilic states, previous thromboembolism, and hospitalisation for congestive heart failure or acute exacerbation chronic obstructive pulmonary disease (COPD). PE and DVT are typically associated with morbidity and mortality. Their natural incidence ranges from 56 events per 100,000 persons to 182 events per 100,000 persons which should be considered against the three deaths from PE in 17 million following vaccination [16-18]. A recent single study from Croatia reported an increase in the prevalence of "combined DVT with PE but not with isolated PE or isolated DVT" [19]. The authors noted from their comparison of non-COVID-19 patients in matched 8-month periods in 2019 pre- and in 2020 during the pandemic a significantly older age group admitted to hospital $(60.8 \pm 17.2$ years $\mathrm{v}$. $68.5 \pm 16.8$ years) [19]. It was postulated that pandemic lockdowns restriction on physical activity may be the cause.

In Europe, a rare disease (AE-adverse event—in this scenario) is defined when it affects five in 10,000 people (prevalence: $500 /$ million). Ultra or very rare AE is defined as when it affects one in 50,000 people or 20 /million. With a simple calculation of 28 thrombotic events reported in relation to the AstraZeneca vaccine for 17 million people who had the vaccine these would be cautiously labelled as extremely rare events [20].

Notably, it would be challenging and difficult to determine the causality and link the thrombotic events to AstraZeneca vaccine using spontaneous reports. Additionally, to apply statistical calculations could be misleading because of the very limited safety and clinical data on the use of vaccine in the people affected, together with under-reporting and the low numbers of exposed individuals. This situation is further complicated by different confounding factors such as the indications and the wide spectrum of unknown comorbidities of patients [21-23].

While the AstraZeneca vaccine has been the focus, other vaccines have also been reporting adverse events. Searching the EMA EV database for Moderna vaccine reports for deep vein thrombosis and pulmonary embolism identified 29 DVTs, of which 12 also had pulmonary embolism; no reported deaths or fatal events [16]. Similarly, searching for the Pfizer vaccine reports, 13 DVTs were found in the same study period, from 17 February to 12 March, as this paper reporting on the AstraZeneca vaccine adverse events. With the Pfizer vaccine, 11 people also developed pulmonary embolism and two died [16].

This study also identified approximately double the occurrence of potential thrombotic events reported in females $(n=19)$ than males $(n=9)$. Thrombotic events in younger females are typically associated with ovarian hyperstimulation syndrome (OHSS) following reproductive treatment $[24,25]$. Although the exact mechanism of developing thrombosis is unknown, it has been postulated that coagulation factors can result in high levels of estradiol hormone [26]. Other specific factors for developing venous thromboembolism (VTE) during pregnancy include caesarean delivery, history of prior VTE, family history of VTE, inherited or acquired thrombophilia, obesity, older maternal age and prolonged immobilization [27].

Additionally, and according to a systematic review and network meta-analysis study, all combined oral contraceptives were associated with an increased risk of venous thrombosis, depending on both the progestogen used and the dose of ethinylestradiol [28].

Currently, the UK Joint Committee on Vaccination and Immunisation (JCVI) advised that vaccination in pregnancy should be considered in women who are frontline health or social care workers or have underlying conditions that put them at very high risk of being infected with, transmitting or experiencing serious complications of COVID-19, however, no details of this group were available for analysis in this study [29].

The vaccine components itself include active immunising antigens, conjugating agents, preservatives, stabilizers, adjuvants, and culture media used in the preparation of the 
vaccine, which can be considered as potential triggers for an allergic reaction. Many delayed reactions are classified as Type III hypersensitivity reactions which are attributed primarily to the formation of immune complexes that including $\mathrm{T}$ cell-mediated processes. The most common signs of delayed-type reactions include rashes, which may include urticaria, erythema and angioedema $[28,29]$.

The limitations of this study include the small number of potential thrombotic adverse events and the limited safety data currently available for the vaccine. There may be under-reporting by healthcare professionals and patients; the quality of reports may play a significant role that may cause false negative or false positive safety signals. Many confounders and incomplete data together with reporting biases may also limit the generalisability of the findings [14].

However, this study has provided valuable information about this current topical area from a trusted database. It has identified a very low number of investigated adverse reactions linked to the AstraZeneca vaccine that could be attributed to multiple causative factors and not merely the vaccines. The EMA's Pharmacovigilance Risk Assessment Committee (PRAC) met on 18 March 2021. It concluded that the AstraZeneca vaccine was safe, effective and the benefits outweighed the risks and so urged people to accept the vaccination when offered [30].

It has been suggested that administration of the COVID-19 vaccine AstraZeneca should be considered carefully and only when the potential benefit outweighs any potential risks, particularly in patients with a history of cerebral venous sinus thrombosis, acquired or hereditary thrombophilia, heparin-induced thrombocytopenia $[29,30]$. Healthcare professionals should be alert to the signs and symptoms of thromboembolism and/orthrombocytopenia. Vaccinated individuals should be instructed to seek immediate medical attention if they develop new symptoms such as shortness of breath, chest pain, leg swelling or unusual skin bruising and/or petechiae after vaccination [31].

Conducting further analyses based on more detailed thrombotic adverse event reports, including patients' characteristics and comorbidities, may enable the assessment of the causality with higher specificity. It must be undertaken by experienced personnel to identify any real risks associated with any and all COVID-19 vaccines.

\section{Conclusions}

This study has identified only 28 thrombotic events linked to the AstraZeneca vaccine out of 54,571 adverse reactions reported on the EV database. This finding should be interpreted cautiously, as underreporting together with reporting biases may limit the generalisability of the findings.

It is difficult to determine a causal effect of the vaccine on the number of thromboembolic diseases reported. No clear causal effect can be confirmed, and multiple causative factors for thrombotic events were untested and undetermined. Further research is required to help national vaccine advisory boards and vaccine resistant people to make better informed, evidence-based decisions.

Author Contributions: Conceptualization, M.T. and H.E.; methodology, M.T. and H.E.; validation, K.M.; formal analysis, H.E. and M.T.; H.E., M.T. and K.M. writing; M.T., H.E. and K.M.-revision based on peer review. All authors have read and agreed to the published version of the manuscript.

Funding: This research received no external funding.

Institutional Review Board Statement: Not applicable.

Informed Consent Statement: Not applicable.

Data Availability Statement: Dataset openly available in the public domain.

Conflicts of Interest: The authors declare no conflict of interest. 


\begin{abstract}
Abbreviations
European Medicines Agency (EMA); European Union (EU); Adverse Reactions (AR); Adverse Drug Reactions (ADR); EudraVigilance (EV); World Health Organization (WHO); Adverse Events Following Immunisation (AEFI); Pulmonary embolism (PE); Deep Vein Thrombosis (DVT); Chronic Obstructive Pulmonary Disease (COPD); ovarian hyperstimulation syndrome (OHSS); UK Joint Committee on Vaccination and Immunisation (JCVI); venous thromboembolism (VTE); EMA's Pharmacovigilance Risk Assessment Committee (PRAC).
\end{abstract}

\title{
References
}

1. Tobaiqy, M.; Qashqary, M.; Al-Dahery, S.; Mujallad, A.; Hershan, A.A.; Kamal, M.A.; Helmi, N. Therapeutic management of patients with COVID-19: A systematic review. Infect. Prev. Pract. 2020, 2, 100061. [CrossRef]

2. Daou, F.; Abou-Sleymane, G.; Badro, D.A.; Khanafer, N.; Tobaiqy, M.; Al Faraj, A. The history, efficacy, and safety of potential therapeutics: A narrative overview of the complex life of COVID-19. Int. J. Environ. Res. Public Health 2021, 18, 955. [CrossRef] [PubMed]

3. Alhumaid, S.; Mutair, A.A.; Alawi, Z.A.; Alhmeed, N.; Zaidi, A.R.Z.; Tobaiqy, M. Efficacy and safety of lopinavir/ritonavir for treatment of COVID-19: A systematic review and meta-analysis. Trop. Med. Infect. Dis. 2020, 5, 180. [CrossRef] [PubMed]

4. Palma, G.; Pasqua, T.; Silvestri, G.; Rocca, C.; Gualtieri, P.; Barbieri, A.; De Bartolo, A.; De Lorenzo, A.; Angelone, T.; Avolio, E.; et al. PI3K $\delta$ inhibition as a potential therapeutic target in COVID-19. Front. Immunol. 2020, 11, 2094. [CrossRef] [PubMed]

5. WHO Official Website. Draft Landscape of COVID-19 Candidate Vaccines. Available online: https://www.who.int/publications/ $\mathrm{m} /$ item/draft-landscape-of-COVID-19-candidate-vaccines (accessed on 3 March 2021).

6. Le Thanh, T.T.; Andreadakis, Z.; Kumar, A.; Román, R.G.; Tollefsen, S.; Saville, M.; Mayhew, S. The COVID-19 vaccine development landscape. Nat. Rev. Drug Discov. 2020, 19, 305-306. [CrossRef] [PubMed]

7. AstraZeneca COVID-19 Vaccine's Summary of Product Characteristics (for Healthcare Professionals). Available online: https: / www.ema.europa.eu/en/documents / product-information/covid-19-vaccine-astrazeneca-product-informationapproved-chmp-29-january-2021-pending-endorsement_en.pdf (accessed on 16 March 2021).

8. Chung, E.H. Vaccine allergies. Clin. Exp. Vaccine Res. 2014, 3, 50-57. [CrossRef] [PubMed]

9. EMA Recommends COVID-19 Vaccine AstraZeneca for Authorisation in the EU. Available online: https://www.ema.europa.eu/ en/news/ema-recommends-covid-19-vaccine-astrazeneca-authorisation-eu (accessed on 3 March 2021).

10. Reg 174 Information for UK Healthcare Professionals. Available online: https://assets.publishing.service.gov.uk/government/ uploads/system/uploads/attachment_data/file/976815/Information_for_Healthcare_Professionals_on_COVID-19_Vaccine_ AstraZeneca.pdf (accessed on 9 April 2021).

11. Voysey, M.; Clemens, S.A.C.; Madhi, S.A.; Weckx, L.Y.; Folegatti, P.M.; Aley, P.K.; Angus, B.; Baillie, V.L.; Barnabas, S.L.; Bhorat, Q.E.; et al. Safety and efficacy of the ChAdOx1 nCoV-19 vaccine (AZD1222) against SARS-CoV-2: An interim analysis of four randomised controlled trials in Brazil, South Africa, and the UK. Lancet 2020, 397, 99-111. [CrossRef]

12. Wise, J. Covid-19: European countries suspend use of Oxford-AstraZeneca vaccine after reports of blood clots. BMJ 2021, 372, n699. [CrossRef] [PubMed]

13. Boytchev, H. Covid-19: Germany struggles with slow uptake of Oxford AstraZeneca vaccine. BMJ 2021, 372, n619. [CrossRef] [PubMed]

14. AstraZeneca. Update on the Safety of COVID-19 Vaccine AstraZeneca 14 March. Available online: https:/ /www.astrazeneca.com/ media-centre/press-releases/2021/update-on-the-safety-of-covid-19-vaccine-astrazeneca.html (accessed on 14 March 2021).

15. AstraZeneca. Update on the Safety of COVID-19 Vaccine AstraZeneca 18 March. Available online: https:/ / www.astrazeneca.com/ media-centre/press-releases/2021/update-on-the-safety-of-covid-19-vaccine-astrazeneca.html (accessed on 18 March 2021).

16. European Medicines Agency. EudraVigilance: European Database of Suspected Adverse Drug Reaction Reports. Available online: http:/ / www.adrreports.eu/en/background.html (accessed on 15 March 2021).

17. Postigo, R.; Brosch, S.; Slattery, J.; van Haren, A.; Dogné, J.M.; Kurz, X.; Candore, G.; Domergue, F.; Arlett, P. EudraVigilance medicines safety database: Publicly accessible data for research and public health protection. Drug Saf. 2018, 41, 665-675. [CrossRef] [PubMed]

18. European Medicines Agency. Access to EudraVigilance Data. Available online: https://www.ema.europa.eu/en/documents/ other/european-medicines-agency-policy-access-eudravigilance-data-medicinal-products-human-use-revision-4_en.pdf (accessed on 12 March 2021).

19. Mahase, E. Covid-19: WHO says rollout of AstraZeneca vaccine should continue, as Europe divides over safety. BMJ 2021, 372 , n728. [CrossRef] [PubMed]

20. Schafer, A.I.; Levine, M.N.; Konkle, B.A.; Kearon, C. Thrombotic disorders: Diagnosis and treatment. Hematol. Am. Soc. Hematol. Educ. Program. 2003, 520-539. [CrossRef] [PubMed]

21. Tapson, V.F. The role of smoking in coagulation and thromboembolism in chronic obstructive pulmonary disease. Proc. Am. Thorac. Soc. 2005, 2, 71-77. [CrossRef] [PubMed] 
22. Slišković, A.M.; Puljević, M.; Šutalo, A.; Bosnić, A.; Banfić, L.; Vrkić Kirhmajer, M. Prevalence of non-COVID-19 venous thromboembolism during SARS-CoV-2 outbreak: Our experience. Cardiol. Croatica. 2021, 16, 71. [CrossRef]

23. Sardella, M.; Lungu, C. Evaluation of quantitative signal detection in EudraVigilance for orphan drugs: Possible risk of false negatives. Ther. Adv. Drug Saf. 2019, 10, 2042098619882819. [CrossRef] [PubMed]

24. Stewart, J.A.; Hamilton, P.J.; Murdoch, A.P. Thromboembolic disease associated with ovarian stimulation and assisted conception techniques. Hum. Reprod. 1997, 12, 2167-2173. [CrossRef] [PubMed]

25. Baumann, P.; Diedrich, K. Thromboembolic complications associated with reproductive endocrinologic procedures. Hematol. Oncol. Clin. N. Am. 2000, 14, 431-443. [CrossRef]

26. O'Connell, K.A.; Wood, J.J.; Wise, R.P.; Lozier, J.N.; Braun, M.M. Thromboembolic adverse events after use of recombinant human coagulation factor VIIa. JAMA 2006, 295, 293-298. [CrossRef] [PubMed]

27. Barletta, J.F.; Cooper, B.; Ohlinger, M.J. Adverse drug events associated with disorders of coagulation. Crit Care Med. 2010, 38 (Suppl. 6), S198-S218. [CrossRef] [PubMed]

28. Stegeman, B.H.; De Bastos, M.; Rosendaal, F.R.; Vlieg, A.V.H.; Helmerhorst, F.M.; Stijnen, T.; Dekkers, O.M. Different combined oral contraceptives and the risk of venous thrombosis: Systematic review and network meta-analysis. BMJ 2013, $347, \mathrm{f} 5298$. [CrossRef] [PubMed]

29. Joint Council on Vaccination and Immunisation. Statement of Immunisation Prioritisation. Available online: https://assets.publishing service.gov.uk/government/uploads/system/uploads/attachment_data/file/950113/jcvi-advice-on-priority-groups-for-covid-19 -vaccination-30-dec-2020-revised.pdf (accessed on 12 March 2021).

30. European Medicines Agency. Emergency Meeting of Pharmacovigilance Risk Assessment Committee (PRAC). Available online: https:/ / www.ema.europa.eu/en/events/extraordinary-meeting-pharmacovigilance-risk-assessment-committee-prac-18 -march-2021 (accessed on 18 March 2021).

31. UK Government. MHRA Issues New Advice, Concluding a Possible Link between COVID-19 Vaccine AstraZeneca and Extremely Rare, Unlikely to Occur Blood Clots. Available online: https://www.gov.uk/government/news/mhra-issues-newadvice-concluding-a-possible-link-between-covid-19-vaccine-astrazeneca-and-extremely-rare-unlikely-to-occur-blood-clots (accessed on 7 April 2021). 